\title{
Activation Failure Including Expansion
}

\section{Failures}

National Cancer Institute

\section{Source}

National Cancer Institute. Activation Failure Including Expansion Failures. NCI Thesaurus.

Code C96715.

Problem associated with the device failing to be activated including expansion. 